\title{
Embryonic Cardiovascular System
}

National Cancer Institute

\section{Source}

National Cancer Institute. Embryonic Cardiovascular System. NCI Thesaurus. Code C34148.

The embryologic differentiation of the heart and blood vessels that is derived from intraand extraembryonic mesoderm, and which begins to develop during the third week of gestation. 